\title{
DETERMINAÇÃo DO PERFIL DE COMPOSTOS VOLÁTEIS E AVALIAÇÃO DO SABOR E AROMA DE BEBIDAS PRODUZIDAS A PARTIR DA ERVA-MATE (Ilex paraguariensis)
}

Carla Carolina Batista Machado e Deborah Helena Markowicz Bastos*

Faculdade de Saúde Pública, Universidade de São Paulo, Av. Dr. Arnaldo, 715, 01246-904 São Paulo - SP, Brasil

Natália Soares Janzantti

Departamento de Alimentos e Nutrição, Faculdade de Ciências Farmacêuticas, Universidade Estadual Paulista, CP 502, 14801-902 Araraquara - SP, Brasil

Roselaine Facanali e Marcia Ortiz M. Marques

Centro de P\&D de Recursos Genéticos Vegetais, Instituto Agronômico de Campinas, CP 28, 13001-970 Campinas - SP, Brasil Maria Regina Bueno Franco

Departamento de Ciências de Alimentos, Faculdade de Engenharia de Alimentos, Universidade Estadual de Campinas, CP 6121, 13083-970 Campinas - SP, Brasil

Recebido em 21/9/05; aceito em 17/7/06; publicado na web em 19/1/07

\begin{abstract}
VOLATILE COMPOUNDS PROFILE AND FLAVOR ANALYSIS OF YERBA MATE (Ilex paraguariensis) BEVERAGES. Volatile compounds from green and roasted yerba mate were analyzed by gas chromatography/mass spectrometry and the flavor profile from yerba mate beverages was determined by descriptive quantitative analyses. The main compounds tentatively identified in green mate were linalool, $\alpha$-terpineol and trans-linalool oxide and in roasted mate were (E,Z)-2,4-heptadienal isomers and 5-methylfurfural. Green mate infusion was qualified as having bitter taste and aroma as well as green grass aroma while roasted mate was defined as having a smooth, slightly burnt aroma. The relationship between the tentatively identified compounds and flavor must be determined by olfatometric analysis.
\end{abstract}

Keywords: yerba mate; volatile compounds; flavor.

\section{INTRODUÇÃO}

Uma das questões fundamentais para a área de alimentos é a relação entre a qualidade percebida pelo consumidor e a presença de compostos responsáveis por seu sabor e aroma, parâmetros essenciais da qualidade de alimentos. Esta abordagem impacta diretamente na indústria, através da definição de índices que se relacionam com a qualidade e, portanto, com o valor agregado do produto $^{1}$.

No caso de infusões, como as de Camellia sinensis (chá verde, oolong e chá preto), o sabor determina a qualidade do produto e seu preço de mercado, evidenciando a importância do conhecimento das rotas bioquímicas de geração dos compostos voláteis, que são em grande parte responsáveis pelo aroma, durante o processamento ${ }^{2-7}$. As lipases presentes nas folhas liberam ácidos graxos insaturados das membranas celulares que, por sua vez, sofrem outras reações de degradação originando compostos voláteis indesejáveis para este produto, como trans-2-hexenal. A degradação de carotenóides leva à formação de compostos responsáveis pelo aroma doce e agradável. A conversão de $\beta$-caroteno em $\beta$-ionona e outros compostos com ionona substituinte e/ou seus produtos de oxidação, bem como a conversão de outros carotenóides em linalol, aldeídos terpênicos e cetonas já foram relatadas e são dependentes da concentração e do tipo de carotenóide presente nas folhas, bem como da presença de antioxidantes, notadamente os polifenóis. Os aminoácidos originam aldeídos que podem ser oxidados a ácidos carboxílicos ou reduzidos a álcoois. A fenilalanina, por ex., sofre desaminação para originar o fenilacetaldeído, composto com aroma floral ${ }^{1-4,6}$.

*e-mail: dmbastos@usp.br
A caracterização da qualidade sensorial de chás depende dos compostos voláteis que dão origem a índices de qualidade, como o VFC ("Volatile Flavor Compounds") e o índice de terpenos ("terpene index") ${ }^{1}$. Os chás considerados mais aromáticos apresentam maiores teores de linalol e seus óxidos e baixos teores de hexanal ${ }^{3,4,8}$.

A erva-mate é uma planta originária da América do Sul, consumida habitualmente na Argentina, Paraguai, Uruguai e Brasil. Das folhas secas desta planta produz-se o tererê e o chimarrão (bebidas à base de erva-mate elaboradas com água fria e quente, respectivamente) e com as folhas secas e torradas prepara-se o chámate. Esta planta chamou a atenção da comunidade científica nos últimos anos por seus efeitos benéficos à saúde humana, principalmente aqueles relacionados à atividade antioxidante e protetora frente a processos degenerativos como, por ex., os que levam ao desenvolvimento de doenças cardiovasculares e a danos ao DNA ${ }^{8}$.

O processamento da erva-mate para produção do chimarrão/ tererê envolve uma etapa de pré-secagem e uma de secagem. Para a produção do chá-mate procede-se a uma etapa de torrefação que submete a erva-mate cancheada a uma temperatura de aproximadamente $120{ }^{\circ} \mathrm{C}$ por $15 \mathrm{~min}$. Tendo em vista o crescente mercado para produtos naturais com propriedades funcionais e a falta de padronização de qualidade para a erva-mate ${ }^{9}$, estudos sobre a descrição sensorial das bebidas à base desta planta e a identificação dos compostos voláteis presentes nas bebidas contribuirão para balizar o desenvolvimento de variedades, as práticas agronômicas e o processamento, visando produtos com maior valor agregado para o mercado interno e internacional, visto que todos estes parâmetros podem influenciar neste aspecto.

Este trabalho teve como objetivos caracterizar o perfil de compostos voláteis presentes em produtos de erva-mate e caracterizar senso- 
rialmente o sabor e o aroma de bebidas à base destes produtos, tendo em vista a possível contribuição odorífera dos compostos presentes.

\section{PARTE EXPERIMENTAL}

\section{Material}

Erva-mate (Ilex paraguariensis) verde e chá-mate do mesmo lote foram obtidas da empresa Leão Jr. S.A., Curitiba, PR, em janeiro de 2004.

A qualidade do chá-mate foi testada em laboratório próprio da empresa, conforme normas da $\mathrm{ANVISA}^{10}$ com relação à higiene de produção e padrões internos, de modo a garantir suas características sensoriais. O preparo do chá-mate envolve a torrefação da ervamate a $120{ }^{\circ} \mathrm{C}$ por $15 \mathrm{~min}$ em forno tipo torrefação de café. O processo foi controlado por sistema automatizado, de forma que a variação de temperatura foi de $\pm 10{ }^{\circ} \mathrm{C}$ e de tempo foi de \pm 3 min.

As amostras de erva-mate verde e chá-mate foram armazenadas em sacos plásticos fechados, em freezer a $-18^{\circ} \mathrm{C}$ até o momento das análises.

\section{Métodos}

\section{Isolamento dos compostos voláteis}

Empregou-se a técnica de hidrodestilação em extrator Clevenger. Para tanto, adicionaram-se $700 \mathrm{~mL}$ de água destilada a $100 \mathrm{~g}$ de cada tipo de erva-mate (verde ou torrada), e submeteu-se à extração por $1 \mathrm{~h}$, à pressão ambiente, a $97{ }^{\circ} \mathrm{C}$. O óleo essencial foi separado da fase aquosa com $1 \mathrm{~mL}$ de diclorometano e a fase orgânica desidratada com sulfato de sódio anidro, armazenada em frasco de vidro e estocada em freezer a $-18{ }^{\circ} \mathrm{C}$. As extrações foram realizadas em triplicata.

\section{Separação e quantificação dos compostos voláteis}

Os isolados contendo os compostos voláteis foram separados por cromatografia gasosa de alta resolução em cromatógrafo gasoso Shimadzu modelo GC-14B, fabricado no Japão, equipado com detector de ionização de chama (CG-DIC) e acoplado a um microcomputador com o programa CLASS-GC10.

Foi utilizada coluna capilar CP-SIL 8 CB (30 m x 0,25 mm x $0,25 \mu \mathrm{m})$. O volume de amostra injetada foi de $3 \mu \mathrm{L}$. O injetor empregado foi do tipo "split", razão 1:32, a temperatura de $250{ }^{\circ} \mathrm{C}$. A temperatura do detector foi de $300{ }^{\circ} \mathrm{C}$. A velocidade linear do gás de arraste, hélio, foi de $45,33 \mathrm{~cm} / \mathrm{s}$ a $60{ }^{\circ} \mathrm{C}$. A programação de temperatura utilizada foi inicial de $60{ }^{\circ} \mathrm{C}$ por $1 \mathrm{~min}$ e depois elevou-se a temperatura até $300{ }^{\circ} \mathrm{C}$, com uma rampa de $3{ }^{\circ} \mathrm{C} / \mathrm{min}$. A quantificação foi feita por normalização e o resultado expresso em porcentagem relativa de área.

\section{Identificação dos compostos voláteis}

Os compostos voláteis presentes nos isolados erva-mate verde e chá-mate foram analisados em cromatógrafo gasoso acoplado a espectrômetro de massas (CG-EM), marca Shimadzu, modelo QP5000, operando por impacto de elétrons (EI, $70 \mathrm{eV}$ ), dotado com coluna capilar DB-5 (30 m x 0,25 mm x 0,25 $\mu \mathrm{m})$.

$\mathrm{O}$ volume de amostra injetada foi de $2 \mu \mathrm{L}$, com o injetor no modo "splitless", a $240{ }^{\circ} \mathrm{C}$. A temperatura da interface foi de 230 ${ }^{\circ} \mathrm{C}$ e gás de arraste, hélio, mantido a uma vazão de $1 \mathrm{~mL} / \mathrm{min}$. A programação de temperatura utilizada foi inicial a $40{ }^{\circ} \mathrm{C}$, elevação até $240{ }^{\circ} \mathrm{C}$, com uma rampa de $3{ }^{\circ} \mathrm{C} / \mathrm{min}$.

A identificação dos compostos voláteis foi efetuada através da comparação dos seus espectros de massas com o banco de dados do sistema (Nist. 62 lib) e pela comparação dos índices de reten- ção de Kovats obtidos experimentalmente com valores tabelados ${ }^{11,12}$. Visto que não foram utilizados padrões para a confirmação positiva da identidade dos compostos, estes foram considerados tentativamente identificados.

Para cálculo do índice de retenção de Kovats, uma mistura de padrões de alcanos (C9 a C24) foi adicionada aos isolados e $2 \mu \mathrm{L}$ injetados no CG-EM nas mesmas condições cromatográficas acima citadas, aplicando-se a equação de Van den Dool e Kratz ${ }^{12}$.

\section{Análise sensorial}

A erva verde foi utilizada para preparo do chimarrão segundo método descrito por Santa Cruz et al. ${ }^{9}$, em que $75 \mathrm{~g}$ de erva-mate verde foram colocados em $1 \mathrm{~L}$ de água mineral a aproximadamente $80^{\circ} \mathrm{C}$. A infusão de chá-mate foi preparada conforme indicação do fabricante, em que $12 \mathrm{~g}$ de erva-mate torrada foram colocados em $1 \mathrm{~L}$ de água a aproximadamente $80{ }^{\circ} \mathrm{C}$. As bebidas foram deixadas em infusão dentro de um béquer tampado com vidro de relógio por 5 min e depois transferidas para garrafa térmica. A cada $1 \mathrm{~h}$ eram preparadas novas bebidas para evitar alterações no sabor.

O perfil de cada bebida à base de erva-mate (chimarrão e chámate) foi desenvolvido pelo método de Análise Descritiva Quantitativa (ADQ). Inicialmente, indivíduos foram recrutados e pré-selecionados com base no poder discriminativo, reprodutibilidade e consenso com a equipe sensorial com relação às características sensoriais das bebidas. Através do método de rede, os provadores foram solicitados a avaliar o aroma e o sabor das bebidas à base de erva-mate, descrevendo suas similaridades e diferenças. Após esta etapa, a equipe sensorial gerou de forma consensual a terminologia descritiva das bebidas, a ficha descritiva das amostras, bem como definições e referências para cada descritor gerado, de acordo com os procedimentos recomendados na ref. 13 .

Para avaliação das amostras, 8 provadores selecionados e treinados utilizaram a ficha previamente desenvolvida que trazia, ao lado de cada descritor, uma escala não estruturada de $9 \mathrm{~cm}$ ancorada nos extremos esquerdo e direito com os termos "nenhum" e "forte", respectivamente.

As amostras foram oferecidas, de forma monádica, apresentadas em taças envoltas com papel alumínio, codificadas com números de 3 dígitos em porções de aproximadamente $50 \mathrm{~mL}$, a $60{ }^{\circ} \mathrm{C}$ (temperatura em que são usualmente consumidas). As análises foram realizadas em triplicata, em cabines individuais sob luz verde para mascarar a aparência. Para eliminar o sabor residual entre uma amostra e outra foram oferecidos biscoitos tipo "cream cracker" e água mineral.

Para análise estatística dos dados foi realizada análise de variância (ANOVA), teste de Tukey $(\mathrm{p} \leq 0,05)$ e Análise dos Componentes Principais (ACP). O programa estatístico utilizado foi o SPSS, versão 11.5 (2002).

\section{RESULTADOS E DISCUSSÃO}

\section{Perfil de compostos voláteis}

$\mathrm{Na}$ fração hidrodestilada da erva-mate verde (Tabela 1) foram identificados tentativamente os seguintes compostos: linalol, $\alpha$ terpineol e trans-óxido de linalol, que correspondem a 69\% da área total dos compostos detectados. Estes compostos estão presentes originalmente nas folhas verdes ou são formados durante o processamento e são enquadrados no grupo de compostos voláteis importantes para a qualidade de Camellia sinensis, por conferirem notas como doce e floral ${ }^{1,4,6}$.

O hidrodestilado de chá-mate (Tabela 2) apresentou compos- 
Tabela 1. Compostos voláteis em chimarrão: índice de Kovats, porcentagem de área relativa, descrição odorífera e padrão de fragmentação

\begin{tabular}{|c|c|c|c|c|c|c|c|c|c|c|c|c|c|}
\hline \multirow{2}{*}{$\begin{array}{l}\text { COMPOSTO* } \\
\text { benzaldeído }\end{array}$} & \multirow{2}{*}{$\begin{array}{c}\text { IK } \\
\text { Calculado }\end{array}$} & \multirow{3}{*}{$\begin{array}{c}\begin{array}{c}\text { IK } \\
\text { Literatura }^{* *}\end{array} \\
961\end{array}$} & \multirow{2}{*}{$\begin{array}{c}\% \\
\text { área } \\
0,64\end{array}$} & \multicolumn{2}{|l|}{ Descrição de Odor ${ }^{* * *}$} & \multicolumn{8}{|c|}{$\begin{array}{l}\text { íons majoritários }(\mathrm{M} / \mathrm{Z}) \\
\text { abundância relativa }(\%)\end{array}$} \\
\hline & & & & Amêndoa, açúcar, queimado & 44 & 40 & 49 & 43 & 51 & 77 & 106 & 105 & 8450 \\
\hline & & & & & 100 & 92 & 51 & 43 & 32 & 26 & 23 & 20 & $17 \quad 12$ \\
\hline \multirow[t]{2}{*}{ isômero do 2,4-heptadienal } & 1006 & - & 3,74 & n.e & 40 & 44 & 81 & 43 & 41 & 49 & 51 & 54 & 5384 \\
\hline & & & & & 100 & 94 & 70 & 48 & 41 & 31 & 23 & 17 & 1613 \\
\hline \multirow[t]{2}{*}{ trans-óxido de linalol } & 1086 & 1088 & 1,20 & n.e & 43 & 40 & 59 & 41 & 49 & 51 & 44 & 81 & 6784 \\
\hline & & & & & 100 & 49 & 35 & 32 & 27 & 21 & 16 & 14 & 1211 \\
\hline \multirow[t]{2}{*}{ linalol } & 1098 & 1100 & 57,43 & Flor,lavanda,alfazema & 41 & 93 & 43 & 91 & 55 & 79 & 119 & 53 & 7740 \\
\hline & & & & & 100 & 70 & 46 & 36 & 29 & 24 & 23 & 23 & 2322 \\
\hline \multirow[t]{2}{*}{ isovalerato de isopentila } & 1102 & 1103 & 3,47 & n.e & 43 & 41 & 57 & 44 & 56 & 55 & 42 & 49 & 7040 \\
\hline & & & & & 100 & 80 & 59 & 45 & 40 & 37 & 29 & 25 & 2020 \\
\hline \multirow[t]{2}{*}{$\alpha$-terpineol } & 1187 & 1189 & 12,18 & Óleo,aniz,menta & 44 & 40 & 43 & 93 & 41 & 59 & 119 & 68 & 9167 \\
\hline & & & & & 100 & 94 & 72 & 71 & 65 & 56 & 52 & 39 & 3634 \\
\hline \multirow[t]{2}{*}{ cis-carveol } & 1226 & 1229 & 2,93 & n.e & 41 & 93 & 40 & 43 & 67 & 119 & 91 & 68 & 7977 \\
\hline & & & & & 100 & 53 & 50 & 45 & 41 & 38 & 38 & 36 & 3331 \\
\hline \multirow[t]{2}{*}{ acetato de di-idrocarveol } & 1304 & 1305 & 7,42 & n.e & 41 & 93 & 43 & 69 & 91 & 79 & 119 & 53 & 6751 \\
\hline & & & & & 100 & 87 & 59 & 58 & 55 & 39 & 38 & 37 & 3431 \\
\hline
\end{tabular}

n.e. $=$ não encontrado; $*$ considerado tentativamente identificado por Espectrometria de Massas e Índice de Kovats; $* *$ ref. $12 ; * * *$ ref. 11

Tabela 2. Compostos voláteis em chá-mate: índice de Kovats, porcentagem de área relativa, descrição odorífera e padrão de fragmentação

\begin{tabular}{|c|c|c|c|c|c|c|c|c|c|c|c|c|c|c|}
\hline COMPOSTO $^{*}$ & $\begin{array}{c}\text { IK } \\
\text { Calculado }\end{array}$ & $\begin{array}{c}\mathrm{IK}^{* *} \\
\text { Literatura }\end{array}$ & $\begin{array}{c}\% \\
\text { área }\end{array}$ & Descrição de Odor ${ }^{* * *}$ & & & & ns $m$ & $\begin{array}{l}\text { ajorit } \\
\text { incia }\end{array}$ & $\begin{array}{l}\text { tários } \\
\text { rela }\end{array}$ & $\begin{array}{l}\text { s (M } \\
\text { tiva }\end{array}$ & $\begin{array}{l}(\mathrm{Z}) \\
(\%)\end{array}$ & & \\
\hline 5-metilfurfural & 951 & 962 & 8,60 & $\begin{array}{l}\text { Amendoa, caramelo, } \\
\text { açucar queimado }\end{array}$ & 53 & 110 & 109 & 51 & 50 & 43 & 52 & 77 & 106 & 105 \\
\hline & & & & & 100 & 53 & 27 & 16 & 14 & 13 & 13 & 12 & 11 & 11 \\
\hline 2,4-heptadienal & 989 & 998 & 8,47 & Noz, gordura & 81 & 41 & 53 & 110 & 51 & 40 & 67 & 68 & 79 & 55 \\
\hline & & & & & 100 & 59 & 49 & 22 & 21 & 21 & 20 & 18 & 17 & 15 \\
\hline isômero do 2,4-heptadienal & 1003 & & 13,16 & - & 81 & 41 & 53 & 51 & 110 & 79 & 40 & 67 & 50 & 77 \\
\hline & & & & & 100 & 52 & 44 & 18 & 18 & 18 & 17 & 17 & 11 & 11 \\
\hline trans- $\beta$-ocimeno & 1051 & 1050 & 0,94 & erva & 68 & 67 & 41 & 93 & 119 & 91 & 53 & 40 & 77 & 51 \\
\hline & & & & & 100 & 63 & 61 & 53 & 45 & 34 & 34 & 30 & 30 & 25 \\
\hline cis-oxido de linalol & 1068 & 1074 & 5,30 & flor & 43 & 59 & 41 & 55 & 71 & 67 & 68 & 81 & 53 & 94 \\
\hline & & & & & 100 & 55 & 40 & 28 & 18 & 17 & 14 & 13 & 13 & 13 \\
\hline t-óxido de linalol & 1084 & 1088 & 4,76 & Batata, torrado & 43 & 59 & 41 & 55 & 67 & 71 & 53 & 68 & 81 & 79 \\
\hline & & & & & 100 & 58 & 55 & 45 & 40 & 27 & 24 & 24 & 24 & 24 \\
\hline linalol & 1096 & 1100 & 1,06 & Flor, lavanda & 41 & 93 & 43 & 119 & 91 & 53 & 69 & 77 & 55 & 67 \\
\hline & & & & & 100 & 58 & 55 & 45 & 40 & 27 & 24 & 24 & 24 & 24 \\
\hline karahanaenona & 1149 & 1155 & 1,83 & n.e. & 41 & 67 & 95 & 43 & 152 & 96 & 40 & 81 & 55 & 53 \\
\hline & & & & & 100 & 57 & 45 & 44 & 37 & 35 & 31 & 31 & 30 & 27 \\
\hline salicilato de metila & 1187 & 1190 & 2,93 & Hortelã-pimenta & 120 & 92 & 152 & 121 & 65 & 63 & 64 & 53 & 93 & 44 \\
\hline & & & & & 100 & 59 & 39 & 32 & 27 & 21 & 19 & 16 & 15 & 12 \\
\hline trans- $\beta$-damascenona & 1378 & 1380 & 0,62 & Maçã, rosa,mel & 44 & 40 & 69 & 41 & 43 & 121 & 45 & 51 & 105 & 91 \\
\hline & & & & & 100 & 59 & 29 & 24 & 17 & 10 & 07 & 06 & 05 & 04 \\
\hline geranil acetona & 1447 & 1453 & 2,10 & Planta, verde & 44 & 43 & 40 & 41 & 69 & 55 & 159 & 53 & 45 & 107 \\
\hline & & & & & 100 & 99 & 54 & 39 & 17 & 10 & 09 & 07 & 06 & 06 \\
\hline$\alpha$-curcurmeno & 1477 & 1483 & 0,70 & erva & 44 & 40 & 43 & 41 & 55 & 105 & 119 & 91 & 79 & 159 \\
\hline & & & & & 100 & 58 & 14 & 10 & 06 & 05 & 05 & 05 & 05 & 05 \\
\hline trans- $\beta$-ionona & 1480 & 1485 & 2,69 & Violeta,alga, framboesa & 44 & 43 & 40 & 117 & 41 & 91 & 55 & 159 & 77 & 53 \\
\hline & & & & & 100 & 80 & 57 & 22 & 21 & 10 & 10 & 08 & 08 & 08 \\
\hline
\end{tabular}

n.e.= não encontrado; $*$ considerado tentativamente identificado por Espectrometria de Massas e Índice de Kovats; ** ref. 12; *** ref. 11

tos (tentativamente identificados) formados a partir da reação de Maillard (5-metilfurfural), além de produtos de degradação de carotenóides que sofreram ou não oxidação (trans- $\beta$-ocimeno, trans e cis-óxido de linalol, trans- $\beta$-damascenona, geranil acetona, trans$\beta$-ionona, $\alpha$-curcumeno) e produtos da degradação de ácidos graxos (2,4-heptadienal). Neste isolado, $14 \%$ dos compostos pertenceram a um grupo de compostos oriundos da degradação de lipídios e que exibem um aroma desagradável descrito como "verde oleoso", enquanto os demais terpenos presentes eram relacionados com características positivas do sabor de Camellia sinensis ${ }^{1,2,4,6,8}$.

Os compostos majoritários no hidrodestilado de erva-mate verde foram linalol (57\%), $\alpha$-terpineol (12\%) e acetato de diidrocarveol (7\%). Enquanto no chá-mate os isômeros $(E, Z)$-2,4-heptadienal $(13 \%)$ e $(E, E)$-2,4-heptadienal $(8 \%)$ e 5-metilfurfural (9\%), além 
de um composto não identificado (22\%), foram os compostos majoritários (Tabela 2).

De acordo com a literatura, os isômeros (2E,4Z)-2,4-heptadienal e (2E,4E)-2,4-heptadienal resultam da degradação de ácidos graxos ${ }^{7}$, sendo que também foram detectados em batatas fritas ${ }^{14}$. No presente estudo, o padrão de fragmentação dos compostos com índice de Kovats 989 e 1003 (Tabela 2) indicaria a presença dos isômeros (E,Z)2,4-heptadienal e (E,E)-2,4-heptadienal, respectivamente.

Segundo Kawakami e Kobayashi ${ }^{15}$ a diferença entre o número de compostos voláteis presentes na erva-mate verde e torrada ocorre devido à reação de Maillard, processo em que são formados novos compostos.

Os isolados apresentaram o aroma característico das bebidas, conforme determinado por uma equipe sensorial treinada e selecionada quanto à capacidade de detectar intensidade de aroma característico de chá-mate e chimarrão. Esta equipe foi a mesma que participou da Análise Descritiva Quantitativa. A avaliação olfatométrica destes isolados seria necessária para identificar quais dos compostos ali presentes seriam os responsáveis pelo aroma e sabor característicos das bebidas.

Bastos et al. ${ }^{16}$ avaliaram uma amostra de erva-mate e de seu produto de torrefação (o chá-mate) provenientes do Paraná, coletados em 2002, pela mesma técnica de isolamento empregada neste estudo e nas mesmas condições. Foi observado um perfil qualitativo diferente de compostos voláteis quando comparado às amostras analisadas neste trabalho. Os autores identificaram limoneno (tentativamente identificado) como o composto mais abundante na fração volátil da erva-mate verde e diversos outros aldeídos e cetonas que não foram identificados neste trabalho. Da mesma forma, para o chá-mate, os autores identificaram perfil diferenciado relativamente a este estudo, indicando variabilidade na matéria-prima. Esta variabilidade, que pode afetar a qualidade sensorial do produto, ocorre também para os produtos de Camellia sinensis, pois, diversos fatores além do processamento influenciam o perfil de compostos voláteis: a variedade, as práticas agronômicas, a idade das folhas e o tempo de armazenamento ${ }^{1,3,6}$.

\section{Análise sensorial}

Os termos previamente levantados para o chimarrão, como “aroma amargo, que lembrou aroma de grama ou mato verde e vem na memória imediatamente o aroma de outros chás como boldo", foram englobados, pela equipe sensorial, em um único termo "aroma característico de chimarrão". Para o chá-mate, o descritor "aroma característico de chá-mate" foi empregado para englobar os termos "aroma suave e quente, com leve sensação de queimado no final, que para alguns foi relacionado ao cigarro".

Os descritores, as definições e referências gerados pela equipe sensorial estão na Tabela 3 . As amostras de bebidas à base de ervamate diferiram significativamente $(\mathrm{p} \leq 0,05)$ entre si em relação a todos os atributos de sabor e aroma julgados (Tabela 4). O chimarrão apresentou maior intensidade dos atributos de "gosto amargo" e "sabor (adstringente e residual)", enquanto o chá-mate caracterizou-se pelo atributo "aroma adocicado" (Figura 1). Resultado similar foi obtido por Togari et al. ${ }^{17}$ que verificaram que o chá preto e oolong apresentaram maior intensidade dos atributos "floral doce" e "frutal doce" quando comparados ao chá verde. A diferença entre estes tipos de chá reside no processamento: o chá verde é constituído das folhas verdes não fermentadas, o oolong sofre fermentação parcial e o chá preto sofre fermentação completa, processo que imprime modificações bioquímicas importantes em termos sensoriais, com a geração de compostos responsáveis pela cor, pela adstringência e pelo aroma e sabor.

Os atributos de sabor e aroma foram analisados pela Análise de Componentes Principais (ACP). Os dois primeiros componentes principais explicaram $99,5 \%$ da variação total que existe entre as

Tabela 3. Definições e referências utilizadas para descrever os atributos de chá-mate e chimarrão

\begin{tabular}{|c|c|c|}
\hline $\begin{array}{l}\text { ATRIBUTO } \\
\text { AROMA }\end{array}$ & DEFINIÇÃO & REFERÊNCIA \\
\hline Característico de chá-mate & $\begin{array}{l}\text { Aroma característico de chá-mate } \\
\text { (erva-mate torrada) (nenhum a forte) }\end{array}$ & $\begin{array}{l}\text { Nenhum: água } \\
\text { Fraco: infusão de chá-mate } \\
\text { utilizando } 1 \text { saquinho de chá para } 300 \mathrm{~mL} \text { de água } \\
\text { Forte: infusão de chá-mate, utilizando } 4 \text { saquinhos } \\
\text { de chá para } 300 \mathrm{~mL} \text { de água }\end{array}$ \\
\hline Característico de chimarrão & $\begin{array}{l}\text { Aroma característico de chimarrão } \\
\text { (erva-mate verde) (nenhum a forte) }\end{array}$ & $\begin{array}{l}\text { Nenhum: água } \\
\text { Fraco: infusão de erva-mate verde } \\
\text { utilizando } 11,25 \mathrm{~g} \text { de erva para } 300 \mathrm{~mL} \text { de água } \\
\text { Forte: infusão de erva-mate verde utilizando } \\
45 \mathrm{~g} \text { de erva para } 300 \mathrm{~mL} \text { de água }\end{array}$ \\
\hline Adocicado & $\begin{array}{l}\text { Aroma característico de doce, } \\
\text { um cheiro bom, suave (nenhum a forte) }\end{array}$ & $\begin{array}{l}\text { Nenhum: água } \\
\text { Forte: solução de água morna com açúcar, } \\
\text { utilizando } 30 \mathrm{~g} \text { de açúcar para } 300 \mathrm{~mL} \text { de água }\end{array}$ \\
\hline
\end{tabular}

SABOR

"Amargo" $\quad \begin{aligned} & \text { Gosto amargo característico } \\ & \text { (nenhum a forte) }\end{aligned}$

Adstringente

Sensação de "amarração" na língua e mucosas bucais (nenhum a forte)

Residual
Aderência do sabor na boca por um tempo depois de engolir (nenhum a forte)
Nenhum: água

Forte: solução de cafeína, utilizando $0,18 \mathrm{~g}$ de cafeína para $300 \mathrm{~mL}$ de água

Nenhum: água

Forte: solução de ácido tânico, utilizando 0,45 g de ácido tânico em $300 \mathrm{~mL}$ de água

Nenhum: água

Forte: solução de extrato de própolis, utilizando 40 gotas de extrato em $300 \mathrm{~mL}$ de água 
Tabela 4. Médias da equipe sensorial para a intensidade dos atributos de aroma e sabor das amostras de bebidas à base de erva-mate

\begin{tabular}{lcc}
\hline ATRIBUTO & CHIMARRÃO & CHÁ-MATE \\
\hline Aroma característico de chá-mate & $0,87^{\mathrm{b}}$ & $7,22^{\mathrm{a}}$ \\
Aroma característico de chimarrão & $6,67^{\mathrm{a}}$ & $0,20^{\mathrm{b}}$ \\
Aroma adocicado & $0,72^{\mathrm{b}}$ & $4,52^{\mathrm{a}}$ \\
Gosto amargo & $7,66^{\mathrm{a}}$ & $2,88^{\mathrm{b}}$ \\
Sabor adstringente & $6,07^{\mathrm{a}}$ & $1,73^{\mathrm{b}}$ \\
Sabor residual & $6,80^{\mathrm{a}}$ & $3,65^{\mathrm{b}}$ \\
\hline
\end{tabular}

Médias com letras diferentes na mesma linha diferem significativamente $(p \leq 0,05)$ entre si pelo teste de Tukey.

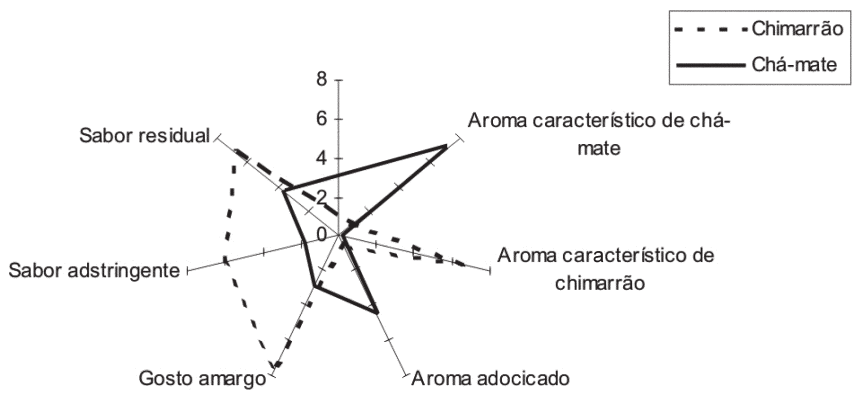

Figura 1. Representação gráfica dos resultados da Análise Descritiva Quantitativa para os atributos aroma e sabor de chá-mate e chimarrão

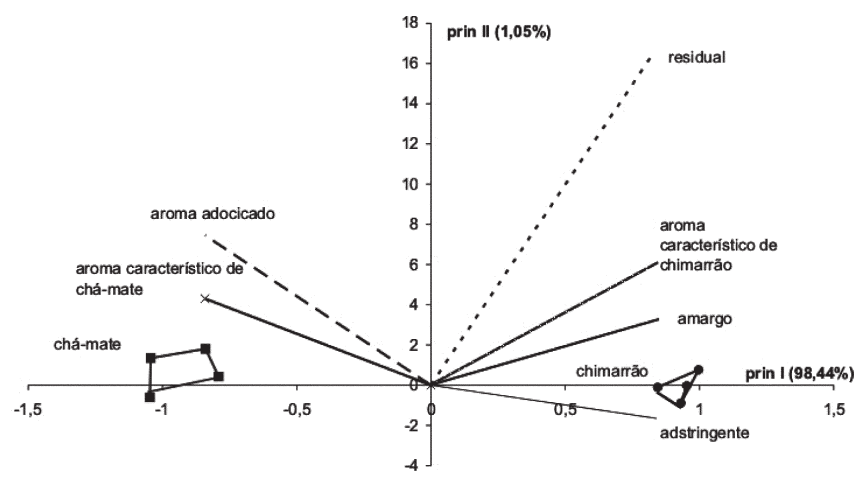

Figura 2. Análise de Componentes Principais (ACP) para sabor e aroma de chá-mate e chimarrão

amostras, sendo que o primeiro explicou $98,4 \%$ desta variação, demonstrando que os descritores empregados discriminaram as amostras analisadas (Figura 2).

Os vetores representam os atributos sensoriais, vetores de tamanho reduzido indicam atributos nos quais as amostras pouco diferem entre si. Observam-se, no gráfico, vetores com tamanhos equivalentes e, portanto, todos os atributos tiveram importância semelhante para explicar as variações entre as amostras. A separação espacial entre as amostras sugere que apresentaram características amplamente distintas entre si, indicativas, em grande parte, do perfil de compostos voláteis diferenciado para cada uma delas.

Grigioni et al. ${ }^{18}$ avaliaram amostras de erva-mate da Argentina usando ADQ e obtiveram os seguintes descritores: aroma de ervamate, aroma de fruta, aroma adocicado, gosto amargo, sabor residual, sabor adstringente, sabor de erva-mate, sabor característico, sabor de chá, sabor verde, amadeirado, rudeza, sensação na boca. Observa-se uma similaridade nos termos encontrados no presente estudo para sabor e aroma de bebidas à base de erva-mate, embora os provadores neste trabalho não tenham familiaridade com a bebida tipo chimarrão.

\section{CONCLUSÕES}

As duas bebidas à base de erva-mate analisadas apresentaram características sensoriais distintas entre si, o que foi confirmado pelo perfil de compostos voláteis. A erva-mate verde apresentou majoritariamente terpenos e aldeídos em sua composição de voláteis tentativamente identificados, o que poderia estar correlacionado com a descrição de "verde, mato". Alguns terpenos em altas concentrações na erva-mate verde foram degradados durante o processo de torrefação. Observou-se ainda a formação de produtos de degradação de carotenóides que provavelmente contribuem, junto com os terpenos, para o aroma doce da bebida.

Ainda não há padrão de qualidade de sabor e aroma para a ervamate, não se tem dados sobre a variação do perfil de compostos voláteis de seus produtos - erva-mate verde e chá-mate - e tampouco existem resultados relacionando a contribuição odorífera dos compostos voláteis presentes nas bebidas com os seus descritores. Tendo em vista o crescimento do mercado nacional e internacional é importante para a indústria ervateira conhecer o que o consumidor considera um produto de qualidade e quais são os fatores a controlar.

Compostos importantes para a qualidade de Camellia sinensis são encontrados também na erva-mate verde e chá-mate ${ }^{15,16}$. É provável que compostos terpênicos, seus óxidos, cetonas e álcoois (limoneno, linalol, óxidos cis e trans linalol), além dos produtos de degradação de carotenóides sejam de importância para a qualidade sensorial destes produtos, no entanto, é imprescindível a avaliação olfatométrica destes compostos para se determinar sua importância odorífera. O estabelecimento de qualidade sensorial, tanto em relação à definição de atributos quanto ao conhecimento dos compostos que respondem por esta qualidade, poderá orientar a indústria ervateira para a obtenção de produtos com maior valor agregado, a exemplo do que ocorre mundialmente com os produtos de Camellia sinensis.

\section{AGRADECIMENTOS}

À FAPESP pela bolsa de mestrado concedida a C. Machado (processo $\mathrm{n}^{\circ}$ 03/03225-1) e pelo auxílio à pesquisa (processo $\mathrm{n}^{\circ} 02 /$ 07645-2) e à empresa Leão Júnior S.A, Curitiba, PR.

\section{REFERÊNCIAS}

1. http://www.rirdc.gov.au/reports/NPP/UQ-61A.doc, acessada em Fevereiro 2006.

2. Ravichandran, R.; Parthiban, R.; J. Sci. Food Agric. 1998, 78, 67; Ravichandran, R.; Parthiban, R.; Food Chem. 1998, 3, 347.

3. Ravichandran, R.; Parthiban, R.; Food Chem. 2000, 68, 7.

4. Ravichandran, R.; Food Chem. 2002, 78, 23.

5. Dudareva, N.; Pichersky, E.; Gershenzon, J.; Plant Physiol. 2004, 135, 1893.

6. Howard, G. E.; Food Chem. 1978, 4, 97.

7. Kato, M.; Shibamoto, T.; J. Agric. Food Chem. 2001, 49,1394; Kumazawa, K.; Masuda, H.; J. Agric. Food Chem. 2001, 49, 3304; Kumazawa, K.; Masuda, H.; J. Agric. Food Chem. 1999, 47, 5169; Owuor, P. O.; J. Sci. Food Agric. 1992, 59, 189; Shimoda, M..; Shigematsu, H.; Shiratsuchi, H.; Osajima,Y.; J. Agric. Food. Chem. 1995a, 43, 1616 ; Shimoda, M.;Shigematsu, H.; Shiratsuchi, H.; Osajima,Y. ; J. Agric. Food Chem. 1995, 43, 1621; Vitzhum, V.; Werkhoff, P.; Hubert, P.; J. Agric. Food Chem. 1975, 23, 999 .

8. Bixby, M.; Spieler, L.;Menini, T.;Gugliucci, A.; Life Sci. 2005, 77, 345; Chandra, S.; Gonzalez, E. M.; J. Agric. Food. Chem., 2004, 52, 3583; Filip, R.; Lolito, S. B.; Ferraro, G.; Fraga, C. G.; Nutr. Res. 2000, 20, 1437; Gugliucci, A.; Menini, T.; Life Sci. 2002, 72, 279; Lunceford, N.; Gugliucci, A.; Fitoterapia 2005, 76, 419; Schinella, G. R.; Troiani, G.; Dávila, V.; Buschiazzo, P. M.; Tournier, H. A.; Biochem. Biophys. Res. Commun. 2000, 269, 357.

9. Santa Cruz, M. J.; Garitta, L.; Hough, G.; Food Sci. Tech. Int. 2002, 8, 25; Santa Cruz, M. J.; Garitta, L.; Hough, G.; Food Sci. Tech. Int. 2003, 9, 347.

10. Brasil, Resolução da Diretoria Colegiada n. 277 de 22 de setembro de 2005; "Regulamento técnico para café, cevada, chá, erva-mate e produtos solúveis". 
11. http://www.flavornet.org, acessada em Março 2005.

12. Adams, R. P.; Identification of Essential Oil Components by Gas Chromatography/Mass Spectroscopy, Allured Publ. Corp.: Illinois, 1995; Jennings, W.; Shibamoto, T.; Qualitative Analysis of Flavor and Fragrance Volatiles by Glass Capillary Gas Chromatography, Academic Press: New York, 1980; McLafferty, F. W.; Tureck F.; Interpretation of Mass Spectra, $4^{\text {th }}$ ed., University Science Books: California, 1993; Van den Dool, H.; Kratz, D. J.; J. Cromatogr. 1963, 11, 463.

13. Meilgaard, M.; Civille, G. V.; Carr, B. T.; Sensory Evaluation Techniques, $3^{\text {rd }}$ ed., Florida: CRC Press, 1999.
14. Wil, A. M.; van Loon, J. P. H.; Linssen, A. L.; Maarten, A.; Posthumus, A. G. J.; Food Chem. 2005, 90, 417.

15. Kawakami, M.; Kobayashi, A.; J. Agric. Food. Chem. 1991, 39, 1275.

16. Bastos, D. H. M.; Ishimoto, E.; Ortiz, M.; Ferri, A; Torres, E.; J. Food Comp. Anal. 2006, 19, 538.

17. Togari, N.; Kobayashi, A.; Aishima, T. ; Food Res. Int. 1995, $28,485$.

18. Grigioni, G.; Carduza, F.; Irurueta, M.; Pensel, N.; J. Sci. Food Agric. 2004, 84,427 